\title{
Prevalence of Candida Species among Vaginitis Symptomatic Pregnant Women Attending Ante-natal Clinic of Anambra State University Teaching Hospital, Awka, Nigeria
}

\author{
Onuorah Samuel $^{1, *}$, Obika Ifeanyi ${ }^{2}$, Okafor Ugochukwu $^{1}$ \\ ${ }^{1}$ Department of Applied Microbiology and Brewing, Nnamdi Azikiwe University Awka, Nigeria \\ ${ }^{2}$ Department of Zoology, Nnamdi Azikiwe University Awka, Nigeria
}

Copyright (C) 2015 Horizon Research Publishing All rights reserved.

\begin{abstract}
Vaginitis is the fungal infection of the vulva and or vagina caused mostly by Candida albicans. Itching, abortion, irritation of the vulva and vagina and white discharges from the vagina are the common symptoms. Thirty vaginitis symptomatic pregnant women attending ante-natal clinic of Anambra State University Teaching Hospital Awka, Nigeria were sampled. They were aged between twenty and forty-five years. The Candida species were isolated, characterized and identified by standard biochemical and microbiological methods. The women aged 26-30 years had the highest percentage distribution of Candida species $(63.3 \%)$ while those in their third trimester of pregnancy were mostly infected, with a percentage distribution of $63.3 \%$. The vaginal candida species isolated from the women were Candida albicans (66.7\%), Candida grabrata $(23.3 \%)$, Candida tropicalis $(6.7 \%)$ and Candida krusei (3.3\%). Candida albicans occurred in all the age groups and trimesters of pregnancy. The pregnant women at great risk of vaginitis are those aged between 26 and 30 years as well as those in their third trimester of pregnancy. This calls for commitment to routine medical examination and appropriate treatment of the infected pregnant women.
\end{abstract}

Keywords Prevalence, Vaginitis, Pregnant Women, Teaching Hospital, Ante-natal Clinic

\section{Introduction}

Vaginitis is the infection of the vulva and or vagina by any species of the yeast Candida, the most common being Candida albicans [1]. Approximately $75 \%$ of all pregnant women experience at least one episode of vaginitis during their life time and $50 \%$ of them suffer multiple episodes [2]. The infection can be acute, chronic, superficial or deep and has wide clinical spectrum. Candida species are almost universal in low numbers on healthy adult skin and are part of the normal flora of the mucous membrane of the respiratory, gastrointestinal and female genital tracts. Overgrowth of these organisms can cause superficial infections such as vaginitis.

The incidence of vaginitis is more remarkable among pregnant women. Several factors can be associated with the increased role of vagina women colonization by Candida species. These include compromised immune system, obesity, diabetes, prolonged use of antimicrobials, HIV/AIDS, pregnancy, poor dietary habits, use of high level of estrogens and oral contraceptives and poor personal hygiene [3-6]. Poorly supported risk factors include the use of sponge, intrauterine devices, diaphragms, condoms, sexual intercourse and diet with high glucose content $[7,8]$.

Vaginitis among pregnant women has also been related to emotional stress and suppression of immune system [9]. During pregnancy, levels of both progesterones and estrogens are elevated. Progesterone has suppressive effects on the anti-candida activity of neutrophils [10] while estrogen has been found to reduce the ability of the vaginal epithelial cells to inhibit the growth of Candida albicans and also decrease immunoglobulins in vaginal secretions resulting in increased vulnerability of pregnant women to vaginitis [11]. Premature neonates are severely endangered because of their immature immune system. During delivery, transmission can occur from the vagina of the infected mother to the newborn, giving rise to congenital infection [12]. This study was therefore undertaken to determine the prevalence of Candida species among vaginitis symptomatic pregnant women attending ante-natal clinic of Anambra State University Teaching Hospital Awka, Nigeria with a view to creating more awareness about this preventable and treatable infection. 


\section{Materials \& Methods}

\subsection{Study Design}

Thirty pregnant women attending ante-natal clinic of Anambra State University Teaching Hospital Awka, Nigeria were sampled. Information regarding their ages and trimester of pregnancy was obtained through the questionnaires completed by them. Their consent was also obtained before the samples were collected and their ages ranged between twenty and forty-five years. The women sampled had symptoms of vaginitis.

\subsection{Sample Collection and Processing}

Thirty vaginal swabs were collected from the vaginitis symptomatic pregnant women. The pregnant women that had itching, dysuria, white discharges from the vagina as well as difficulty in walking were deemed symptomatic. Vaginal swab samples were collected from ten pregnant women per day to allow for their processing on the same day. The samples were collected within the period of August, 2014.

A sterile cotton-wool swab stick was inserted into the endocervical canal and gently rotated against the wall of the endocervix. The swab stick was then withdrawn and replaced in its casing and labeled appropriately with the patient's information. The women were placed according to their ages into the following age groups: 20-25, 26-30, 31-35, $36-40$ and $41-45$ years. They were also stratified according to the trimester of pregnancy into first, second and third trimesters.

\section{Laboratory Analysis}

\subsection{Gram Stain}

Smears were made from the vaginal swabs, stained using the gram stain procedure and examined under the microscope for the presence of gram positive budding yeast cells with pseudohyphae.

\subsection{Culture Procedure}

Each of the vaginal swabs was aseptically inoculated on sabouraud dextrose agar (SDA) supplemented with two percent chloramphenicol to inhibit bacterial growth. The inoculated plates were incubated at $37^{\circ} \mathrm{C}$ for 48 hours and examined for cream coloured colonies and budding yeast cells. The colonies were purified by repeated subculturing on sterile SDA plates and later stored on sterile SDA slants for further tests.

\subsection{Chlamydospores Formation Test}

The method of Menza et al [13] was used. The isolates (48 hour old yeast colonies) were inoculated by streaking in corn meal agar containing tween 80 and incubated at $25^{\circ} \mathrm{C}$ for 72 hours. The isolates were thereafter stained with lactophenol cotton blue on a slide and examined under the microscope for chlamydospore formation.

\subsection{Germ Tube Test}

The procedure of Menza et al [13] was used in performing the test. A colony of the test yeast cell was inoculated in human serum and incubated at $37^{\circ} \mathrm{C}$ for 3 hours. A drop of the incubated serum was placed on a microscope slide and covered with a cover slip and examined under the microscope for the presence of germ tube. This is a presumptive test for the identification of Candida albicans.

\subsection{Sugar Assimilation Test}

The procedure of Menza et al [13] was used in carrying out the test. Carbohydrate impregnated filter paper discs were placed on sterile carbohydrate-free yeast nitrogen base agar contained in petri dishes and incubated at $30^{\circ} \mathrm{C}$ for 18 hours. The presence of growth around the carbohydrate-free filter paper discs was thereafter observed. The presence of growth in the medium indicated the ability of the isolate to assimilate a sugar. The sugars used were glucose, lactose, sucrose and galactose.

\subsection{Motility Test}

Hanging drop slides were used. Vaseline was spread with a sterile toothpick on the four corners of a clean coverslip. A drop of the yeast suspension was aseptically placed in the centre of the coverslip with a sterile inoculating loop. The depression slide was lowered, with the concavity facing down, onto the coverslip so that the drop protruded into the centre of the concavity of the slide. The hanging drop slide was turned over and placed on the stage of the microscope so that the drop was over the light hole. The drop was thereafter examined under the microscope.

\subsection{Urease Test}

The surface of a Urea agar slant was streaked with a portion of the test organism. The cap of the tube was left on loosely and the test tube was incubated at $37^{\circ} \mathrm{C}$ for 48 hours and observed for colour change from light orange to bright pink which was an indication that the organism produced the enzyme Urease.

\section{Results and Discussion}

The prevalence of Candida species among Vaginitis Symptomatic Pregnant women attending ante-natal clinic of Anambra State University Teaching Hospital Awka, Nigeria 
was studied. Thirty pregnant women aged between twenty years and forty-six years who attended the ante-natal clinic during the month of August 2014 were sampled.

The percentage distribution of vaginitis according to the age groups of the pregnant women showed that $10 \%(\mathrm{n}=3)$ were in the age group of $20-25$ years, $63.3 \%(\mathrm{n}=19)$ in the age group of $26-30$ years, $16.7 \%(n=5)$ in the age group of $31-35$ years, $6.7 \%(n=2)$ in the age group of $36-40$ years while $3.3 \%(n=1)$ was in the age group of $41-45$ years (Table 1).

Table 1. Percentage distribution of vaginitis according to the age groups of the pregnant women.

\begin{tabular}{|c|c|c|}
\hline $\begin{array}{c}\text { Age group } \\
\text { (yrs) }\end{array}$ & $\begin{array}{c}\text { Number of pregnant women } \\
\text { sampled }\end{array}$ & Distribution (\%) \\
\hline $20-25$ & 3 & 10.0 \\
\hline $26-30$ & 19 & 63.3 \\
\hline $31-35$ & 5 & 16.7 \\
\hline $36-40$ & 2 & 6.7 \\
\hline $41-45$ & 1 & 3.3 \\
\hline
\end{tabular}

The high percentage distribution of vaginitis in the age group 26-30 years may be because members of the age group are sexually active and use drugs and contraceptives indiscriminately. The incidence rates of vaginitis among the women within the age group 26-35 years and 20-30 years were $80.0 \%$ and $73.3 \%$ respectively.

Menza et al [13] however reported an incidence rate of $60 \%$ within the age group 26-35 years in Kenya, Sehgal et al [14] reported an incidence rate of $54 \%$ within the age bracket 20-30 years in Northern Nigeria while Okungbowa et al [15] and Akortha et al [16] reported incidence rates of $55 \%$ and $57 \%$ respectively within the age group 26-35 years in Benin City, Edo State, Nigeria. Women in the age group 41-45 years are close to their menopause and are less active sexually. They also rarely use contraceptives to prevent pregnancy and have increased vaginal immunity due to decreased levels of estrogens and corticoids. In this study, the percentage distribution of vaginitis in the women aged $36-45$ years was $10.0 \%$. This result is in agreement with Okungbowa et al [15] who reported a prevalence rate of $10 \%$ within the age group of 36-45 years and concluded that it was probably due to the possible increase in vaginal immunity.

The percentage distribution of vaginitis according to the trimester of pregnancy showed that $10.0 \%(\mathrm{n}=3)$ were in the first trimester, $26.7 \%(\mathrm{n}=8)$ in the second trimester and $63.3 \%(\mathrm{n}=19)$ were in the third trimester of pregnancy (Table 2).

Table 2. Percentage distribution of vaginitis according to the trimester of pregnancy

\begin{tabular}{|c|c|c|}
\hline $\begin{array}{c}\text { Trimester of } \\
\text { Pregnancy }\end{array}$ & $\begin{array}{c}\text { Number of pregnant } \\
\text { Women sampled }\end{array}$ & Distribution (\%) \\
\hline First & 3 & 10.0 \\
\hline Second & 8 & 26.7 \\
\hline Third & 19 & 63.3 \\
\hline
\end{tabular}

The high percentage distribution of vaginitis among the pregnant women in their third trimester of pregnancy was because pregnant women in that trimester of pregnancy have suppressed immune system which may be due to emotional stress which increases as child birth approaches, increased levels of estrogens and corticoids which decrease vaginal defense mechanisms, vaginal and pelvic examinations in preparation to delivery which predispose the mother to greater chances of vaginitis and reduction in the hygiene status of some pregnant mothers such as failure to wash their undies and private parts properly due to fatigue or stomach size. Pregnant women in their first and second trimesters of pregnancy have low emotional stress and strong immune system against Candida species infections. Sobel et al [9] however reported prevalence rates of $11 \%$ and $20 \%$ in pregnant women in their first and second trimesters of pregnancy respectively. Olowe et al [17] reported that the prevalence of vulvovaginal candidiasis to be highest in the third trimester of pregnancy as virtually all the women they examined had candidiasis compared with $37.5 \%$ of those in their second and $25 \%$ of first trimester pregnancies.

The percentage occurrence of vaginal Candida species in the pregnant women showed that $66.7 \%(\mathrm{n}=20)$ were Candida albicans, $23.3 \%(\mathrm{n}=7)$ were Candida glabrata, $6.7 \%$ $(\mathrm{n}=2)$ were Candida tropicalis while $3.3 \% \quad(\mathrm{n}=1)$ was Candida krusei (Table 3).

Table 3. Percentage occurrence of vaginal Candida species in the pregnant women

\begin{tabular}{|c|c|c|}
\hline Vaginal candida species & Number isolated & Occurrence (\%) \\
\hline Candida albicans & 20 & 66.7 \\
\hline Candida glabrata & 7 & 23.3 \\
\hline Candida tropicalis & 2 & 6.7 \\
\hline Candida krusei & 1 & 3.3 \\
\hline
\end{tabular}

Cnadida albicans was the most common vaginal Candida species isolated in this study. This may be as a result of the predominance of the yeast over the other species. This result is in agreement with Akortha et al [16] and Abu-Elteen et al [18] who reported Candida albicans as the most common vaginal Candida species isolated in the pregnant women they studied. The percentage occurrence of non-Candida albicans in this study was $33.3 \%$ indicating that they are becoming significant pathogens.

The distribution of the vaginal Candida species according to the age groups of the pregnant women showed that all the vaginal Candida species were isolated from the pregnant women within the age group of 26-30 years. Candida albicans occurred in all the age groups studied while C. tropicalis and C. krusei were only isolated from women within the age group of 26-30 years and C. glabrata in the age group of 20-25 and 26-30 years (Table 4). 
Table 4. Distribution of the vaginal Candida species according to the age groups of the pregnant women.

\begin{tabular}{|c|c|c|c|c|c|}
\hline $\begin{array}{c}\text { Vaginal } \\
\text { candida } \\
\text { species }\end{array}$ & $\begin{array}{c}20-25 \text { years } \\
(\mathrm{n})\end{array}$ & $\begin{array}{c}26-30 \text { years } \\
(\mathrm{n})\end{array}$ & $\begin{array}{c}31-35 \\
\text { years } \\
(\mathrm{n})\end{array}$ & $\begin{array}{c}36-40 \\
\text { years } \\
(\mathrm{n})\end{array}$ & $\begin{array}{c}41-45 \\
\text { years } \\
(\mathrm{n})\end{array}$ \\
\hline $\begin{array}{c}\text { Candida } \\
\text { albicans }\end{array}$ & 2 & 13 & 3 & 2 & 1 \\
\hline $\begin{array}{c}\text { Candida } \\
\text { glabrata }\end{array}$ & 1 & 3 & 2 & 0 & 0 \\
\hline $\begin{array}{c}\text { Candida } \\
\text { tropicalis }\end{array}$ & 0 & 2 & 0 & 0 & 0 \\
\hline $\begin{array}{c}\text { Candida } \\
\text { krusei }\end{array}$ & 0 & 1 & 0 & 0 & 0 \\
\hline
\end{tabular}

$\mathrm{n}=$ number of isolates

The distribution of the vaginal Candida species was highest within the age group of 26-30 years $(63.3 \%)$. Candida albicans had the highest distribution of $66.7 \%$ within this age group. The distribution of vaginal Candida species within the age group of 20-30 years was $73.3 \%$. Sehgal [14] however reported a $54 \%$ distribution of vaginal Candida species within the age group of 20-30 years in Northern Nigeria. The distribution of vaginal Candida species within the age group of 41-45 years was low (3.3\%).

The high distribution of the vaginal Candida species within the age group of 26-30 years may be because women within this age group are sexually active, abuse antibiotics and use contraceptives to prevent pregnancy thereby reducing their vaginal immunity while the low distribution within the age group of 41-45 years was because of increased vaginal immunity occasioned by the fact that the women within the age group are less sexually active and rarely abuse antibiotics. They also rarely use contraceptives to prevent pregnancy. These results agreed with those of Akortha et al [16].

The distribution of vaginal Candida species according to the trimester of pregnancy showed that $10.0 \%(n=3)$ were isolated in the first, $26.7 \%(n=8)$ in the second and $63.3 \%$ $(n=19)$ in the third trimesters of pregnancy (Table 5).

Table 5. Distribution of vaginal Candida species according to trimester of pregnancy

\begin{tabular}{|c|c|c|c|c|}
\hline $\begin{array}{c}\text { Trimester of } \\
\text { pregnancy }\end{array}$ & $\begin{array}{c}\text { Candida } \\
\text { albicans } \\
(\mathrm{n})\end{array}$ & $\begin{array}{c}\text { Candida } \\
\text { grabrata } \\
\text { (n) }\end{array}$ & $\begin{array}{c}\text { Candida } \\
\text { tropicalis } \\
(\mathrm{n})\end{array}$ & $\begin{array}{c}\text { Candida } \\
\text { krusei } \\
(\mathrm{n})\end{array}$ \\
\hline First & 3 & 0 & 0 & 0 \\
\hline Second & 5 & 2 & 1 & 0 \\
\hline Third & 12 & 4 & 2 & 1 \\
\hline
\end{tabular}

$\mathrm{n}=$ number of isolates

Candida albicans was isolated from the pregnant women in all the three trimesters of pregnancy because it is the most common vaginal species causing candidiasis. Candida glabrata and C. tropicalis were isolated in the second and third trimesters of pregnancy only while C. krusei was isolated in the third trimester of pregnancy only.

The highest number of vaginal Candida species (63.3\%) was isolated during the third trimester of pregnancy. This result is in agreement with that of Sobel et al [19] who isolated Candida species at a rate of $67 \%$ in the third trimester of pregnancy and attributed it to increased emotional stress as a pregnant mother is expecting a child and decreased level of vaginal defense mechanisms. Vaginal Candida species occurred less frequently in the first and second trimesters of pregnancy due to the fact that women in those trimesters of pregnancy have reduced emotional stress and strong defense mechanism against Candida species. Candida albicans was the most frequently vaginal Candida species causing vaginitis in the three trimesters of pregnancy indicating that it is the most common cause of vaginitis in pregnant women.

\section{Conclusions}

The prevalence of Candida species among vaginitis symptomatic pregnant women studied was high in the women within the age group of 26-30 years and in those women in their third trimester of pregnancy. Candida albicans was the most common of the vaginal candida species isolated and it occurred in all age groups and trimesters of pregnancy, therefore routine medical examination, adequate ante-natal services and appropriate treatment of the infected women are inevitable.

\section{REFERENCES}

[1] D.A. Eschenbach. Chronic vulvovaginal candidiasis. The New England Journal of Medicine. Vol 351, 2554-2556, 2004. DOI: 10.1056/NEJM 200412093512419

[2] P.1. Fidel, J. cutright, C. Steele. Effects of reproduction hormones on experimental vaginal candidiasis. Infection and Immunity. Vol 68, No.2, 651-657, 2000 DOI: 10.1128/IAI.68.2.651-657.2000

[3] P.A. Akah, C.E. Nnamani, P.O. Nnamani. Prevalence and treatment outcome of vulvovaginal candidiasis in pregnancy in a rural community in Enugu State, Nigeria. Journal of medicine and medical sciences. Vol 1, No. 10, 477-452, 2010. http//www. researchgate.net/publication/228337744

[4] J.A. Alli, I.O. Okonko, N.N. Odu, A.F. Kolade, J.C. Nwanze. Detection and prevalence of candida isolates among patients in Ibadan, Southwestern Nigeria. Journal of Microbiology and Biotechnology Research. Vol. 1, No.3, 176-184, 2011 $\mathrm{http} / / \mathrm{www}$. researchgate.net/publication/267409458

[5] J.J. Barlette, A.O. Berg, F.E. Heidrich. Clinical Comparison of microscopic and culture techniques in the diagnosis of vaginal infections. Journal of family practice. Vol. 2 No. 3 , 24-33, $1999 \mathrm{http} / / \mathrm{www} . j$ fponline.com/home/article

[6] P.A. Feyi-Waboso, A.N. Amadi. The prevalence and pattern of vaginal candidiasis in pregnancy in Abia. Journal of Medical Investigation and Practice. Vol 2, 25-27, 2001. http//www. ajol.info/index-php/jomip/article/view/28976

[7] B.D. Reed, P Zazove, C.L. Pierson, D.W. Gorenflo, J. Honocks. Candida transmission and sexual behaviours as 
risks for a repeat episode of candida vulvovaginitis. Journal of Women Health. Vol. 2, No. 10, 979-989,2003. DOI: $10.1089 / 154099903322643901$

[8] E.M. de leon, S.J. Jacober, J.D. Sobel, B. Foxman. Prevalence and risk factors for vaginal candida colonization in women with type 1 and type 2 diabetes. BMC Infectious Diseases. Vol,2 No. 1, 1110-1116, 2002. DOI: $10.1186 / 1471-2334-2-1$

[9] J.D. Sobel. Vaginitis. The New England Journal of medicine. Vol. 337, 1896-1903,1997. DOI: 10.1056/NEJM 199712253372607

[10] T. Nohmi, S. Abe, K. Dobashi, S. Tansho, H. Yamaguchi. Suppression of anti-candida activity of murine neutrophils by progesterone in vitro: a possible mechanism in pregnant women's vulnerability to vaginal candidiasis. Microbiology and Immunology, Vol 39, No. 6, 405-409, 1995. DOI: 10.1111/j. 1348-0421.1995.tbo2220.x

[11] C.R. Wira, R.A. Rossoll. Antigen-presenting cells in the female reproductive tract: influence of sex hormones on antigen presentation in the vagina. Immunology. Vol. 84, No. 4, 505-508, 1995. http://www. ncbi. n/m.gov/pmc/articles/PMC 1415167

[12] D. Novakowska, A. Kurnafiwska, B. Stray-Pederson, J. Wilczynski. Prevalence of fungi in the vagina, rectum and oral cavity in pregnant diabetic women relation to gestational age and symptoms. Acta Obstetricia et Gynecologica. Vol.83, No. 3, 251-256, 2004. DOI: 10.1111/j. 0001-6349.2004.0361.x

[13] N. Menza, W. Wanyoike, W.M. Muturi. Prevalence of Vaginal candidiasis and determination of the occurrence of Candida species in pregnant women attending the ante-natal clinic of thika district hospital, Kenya. Open Journal of
Medical Microbiology. Vol 3, No. 4, 1-9, 2013. DOI: 10.4236/ojmm.2013.34040

[14] S.C. Sehgal. Epidemiology of male urethritis in Nigeria. The Journal of Tropical medicine and hygiene. Vol 93, No.2, 151-152, 1990. http://www.researchgate.net/publication/210 47130

[15] F.I. Okungbowa, O.S. Isuehumhen, A.P. Debe. The distribution frequency of Candida species in the genitourinary tract among symptomatic individuals in Nigerian Cities. Revista iberoamericana de micologia. Vol 20, No. 2, 60-63, 2003. http://www. reviberoammicol .com/2003-20/06006

[16] E.E. Akortha, N.O. Chinwe, V.O. Nwaugo. Antifungal resistance among Candida species from patients with genitourinary tract infection isolated in Benin City, Edo State Nigeria. African Journal of Microbiology Research. Vol 3, No. 11, 694-699, 2009. http://www.academicjournals.org/journal/AJMR/article-abstr act/B5182DA14604

[17] O.A. Olowe, O.B. Makanjuola, R. Olowe, D.A. Adekunle. Prevalence of vulvovaginal candidiasis, Trichomoniasis and Bacterial Vaginosis among Pregnant Women Receiving Ante-natal Care in Southwestern Nigeria. European Journal of Microbiology and Immunology. Vol4, No.4, 193-197, 2014. DOI: 10.1556/EUJMI-D-14-00027.

[18] K. Abu-Eiteen, A.M.M. Abdulmalek, N.A. Abdul Wahed. Prevalence and susceptibility of vaginal yeast isolates in Jordan. Mycoses. Vol 40, No. 5-6, 179-185, 1997. DOI: 10.1111/j. 1439-0507.1997. tboo211.x

[19] J.D. Sobel. Vaginitis. The New England journal of Medicine. Vol, 338, 1548-1549,1998 DOI:10.1056/NEJM199805213382116 